\title{
RESPONSABILIDADE CIVIL DO ESTADO EM FACE DOS ATOS DE REGISTRADORES E NOTÁRIOS
}

Civil liability of the state in the light of the acts of registrars and notaries

Paula Ongaratto Trentin ${ }^{1}$

${ }^{1}$ Graduanda do sexto semestre em Ciências Sociais e Jurídicas na Universidade Regional Integrada do Alto Uruguai e das Missões - URI Erechim.E-mail: paula_trentin@hotmail.com

Data do recebimento: 30/08/2019 - Data do aceite: 09/04/2020

RESUMO: Diante da possibilidade de responsabilização do Estado pelos atos praticados por registradores e notários, faz-se necessária a realização da presente pesquisa com vistas a analisar os limites de tal responsabilização, bem como suas implicações práticas e teóricas. Para tanto, realiza-se uma breve caracterização da responsabilidade civil e de suas principais espécies. Posteriormente, passa-se à análise da responsabilidade do Estado, especialmente em face dos atos de seus agentes delegados. Nesse ponto, realiza-se uma breve análise histórica seguida do estudo do RE 842.846 do STF, e da Lei ${ }^{\circ}$ 13.268/16, apontando-se a responsabilidade objetiva e direta do Estado, bem como a responsabilidade subsidiária dos registradores e notários. Ademais, constata-se a superveniência de problemas de ordem processual e financeira oriundos do entendimento firmado pela Suprema Corte brasileira. Destaca-se que, para a realização da pesquisa, utilizou-se o método indutivo, com consulta bibliográfica, tendo como fontes livros, artigos e a legislação brasileira.

Palavras-chave: Responsabilidade Civil. RE 842.846 STF. Lei no 13.268/16. Registradores. Notários.

Abstract. Given the possibility of State responsibility for the acts practiced by registrars and notaries, it is necessary to conduct the present research in order to analyze the limits of such responsibilities, as well as its practical and theoretical implications. Therefore, a brief characterization of civil liability 
and its main species is carried out. Subsequently, the analysis of the responsibility of the State, especially in the light of the acts of its delegated agents. At this point, a brief historical analysis is carried out followed by the study of RE 842.846 of the STF, and Law No. 13.268 / 16, indicating the objective and direct responsibility of the State, as well as the subsidiary responsibility of registrars and notaries. In addition, there is supervenience of procedural and financial problems stemming from the understanding established by the Supreme Brazilian Court. It should be emphasized that for this research the inductive method was used, with bibliographical review, having books, articles and the Brazilian legislation as sources.

Keywords: Civil liability. RE 84.846 STF. Law $n^{\circ}$. 13.268/16. Registrars. Notaries.

\section{Introdução}

O presente artigo propõe uma breve reflexão acerca da responsabilidade do Estado perante os atos dos registradores e notários. Justifica-se a realização desta pesquisa diante da relevância do tema para a sociedade, considerando que a possibilidade de onerar o Estado repercute diretamente sobre os seus cidadãos. Ademais, verifica-se que com o advento da Lei $\mathrm{n}^{\mathrm{o}} 13.268 / 16$, tida como inconstitucional por parte da doutrina, e a mudança da ótica da responsabilização dos próprios notários e registradores, faz-se imperiosa a análise do tema visando resguardar a segurança jurídica do ordenamento jurídico brasileiro.

Nesse toar, analisa-se, primeiramente, a responsabilidade civil, distinguindo-a em objetiva e subjetiva, bem como em subsidiária e solidária. Tal diferenciação conceitual é imprescindível para que, posteriormente, seja possível analisar, de forma específica, a responsabilidade estatal. Por fim, estuda-se a responsabilidade estatal perante os atos dos notários e dos registradores, realizando preliminarmente uma concisa análise histórica e, em seguida, adentrando no ponto-chave desta pesquisa, a Lei $n^{\circ} 13.268 / 16$, a decisão paradigma RE 842.846 STF e os debates doutrinários oriundos destas.

Nesse ínterim, tem-se como objetivo geral analisar as implicações geradas pela Lei $n^{\circ}$ 13.268/16 e pela decisão RE 842.846 STF no que tange à responsabilidade do Estado perante os atos dos registradores e notários. Para tanto, torna-se necessária a delineação, de forma específica, da responsabilidade civil e de suas principais classificações, bem como da responsabilidade do Estado. Ademais, a fim de facilitar o raciocínio crítico objetivado, faz-se preciso a realização de uma breve análise histórica da responsabilização do Estado ante os atos dos registradores e notários, para, enfim, ser possível abordar a problemática da presente pesquisa.

Ressalta-se que na formulação do presente artigo é utilizado o método indutivo, haja vista a inexistência de uma premissa geral sobre a temática, sendo esta formulada a partir das circunstâncias que se analisa. Destaca-se que os recursos empregados foram exclusivamente bibliográficos, tendo como principais fontes livros, artigos e a legislação brasileira. 


\section{Responsabilidade Civil}

A responsabilidade civil nasce de uma conduta humana voluntária violadora de um dever jurídico, ou seja, de um ato jurídico, lícito ou ilícito. Para que esta responsabilidade se configure, faz-se necessária a conjugação de alguns elementos essenciais, elencados pelo Código Civil, no artigo 186, quais sejam, ação ou omissão, culpa (negligência, imprudência ou imperícia) ou dolo do agente, relação de causalidade e dano (GONÇALVES, 2018). Nesse toar, Pereira (2018, p. 13) assenta que "a responsabilidade civil consiste na efetivação da reparabilidade abstrata do dano em relação a um sujeito passivo da relação jurídica que se forma".

Destaca-se que o ordenamento jurídico brasileiro optou pela concepção privatística da responsabilidade civil, de modo que aquele que gerou o dano tem o dever de repará-lo; todavia, fica ao arbítrio do lesado postular o ressarcimento ou deixar de fazê-lo (PEREIRA, 2018). Ressalta-se que:

O art. 929 (art. 927 do Código Civil de 2002) estabelece que o agente do ilícito danoso é obrigado a reparar o dano [...] sua análise, porém, no contexto geral, revela que a reparação do dano é um direito do lesado, que pode exercê-lo ou deixar de o fazer, como pode, ainda, eximir o agente mediante cláusula expressa, ou transferir para um terceiro o dever ressarcitório mediante contrato de seguro (PEREIRA, 2018, p. 16).

\section{Responsabilidade Civil Objetiva e Subjetiva}

Nessa conjuntura, é fundamental a diferenciação entre responsabilidade civil objetiva e subjetiva, mediante a análise da prescindibilidade ou da imprescindibilidade do elemento culpa para sua configuração (GONÇALVES, 2018). Destaca Gonçalves (2018, p. 48) que "conforme o fundamento que se dê a responsabilidade, a culpa será ou não considerada elemento da obrigação de reparar o dano". Assim, surgem duas teorias divergentes para a caracterização da responsabilidade: a teoria da culpa e a teoria do risco.

A teoria da culpa, também denominada de teoria subjetiva, vê a culpa como elemento imprescindível para a responsabilização civil, haja vista a necessidade de que o agente atue de forma dolosa ou culposa para a ocorrência do dano. Caso não seja verificado o elemento fundante culpa ou dolo, inexistirá responsabilidade (GONÇALVES, 2018). Nesse sentido, Pereira (2018, p. 39) observa:

A essência da responsabilidade subjetiva vai assentar, fundamentalmente, na pesquisa ou indagação de como o comportamento contribui para o prejuízo sofrido pela vítima. Assim procedendo, não considera apto a gerar o efeito ressarcitório um fato humano qualquer. Somente será gerador daquele efeito uma determinada conduta que a ordem jurídica reveste de certos requisitos ou de certas características. Assim considerando, a teoria da responsabilidade subjetiva erige em pressuposto da obrigação de indenizar, ou de reparar o dano, o comportamento culposo do agente, ou simplesmente a sua culpa, abrangendo no seu contexto a culpa propriamente dita e o dolo do agente.

A teoria do risco ou objetiva, por sua vez, defende que a reparação do dano independe de culpa ou dolo do agente, bastando o dano e o nexo de causalidade para sua configuração. Trata-se, pois, de responsabilidade legal, haja vista que parte do pressuposto de que "todo dano é indenizável, e deve ser 
reparado por quem a ele se liga por um nexo de causalidade, independentemente de culpa" (GONÇALVES, 2018, p. 48). Nessa acepção, corrobora Pereira (2018, p. 345):

A doutrina objetiva, ao invés de exigir que a responsabilidade civil seja a resultante dos elementos tradicionais (culpa, dano, vínculo de causalidade entre uma e outro) assenta na equação binária cujos polos são o dano e a autoria do evento danoso. Sem cogitar da imputabilidade ou investigar a antijuridicidade do fato danoso, o que importa para assegurar o ressarcimento é a verificação se ocorreu o evento e se dele emanou o prejuízo. Em tal ocorrendo, o autor do fato causador do dano é o responsável. Com a teoria do risco, diz Philippe Le Tourneau, o juiz não tem de examinar o caráter lícito ou ilícito do ato imputado ao pretenso responsável: as questões de responsabilidade transformam-se em simples problemas objetivos que se reduzem à pesquisa de uma relação de causalidade.

\section{Responsabilidade Civil Subsidiária e Solidária}

Também se faz necessária a distinção entre responsabilidade subsidiária e solidária, a fim de definir quem deve assegurar a reparação do dano. Nesse viés, a responsabilidade será subsidiária quando há um responsável principal e um responsável subsidiário, sendo que este apenas responderá pela obrigação se aquele não cumpri-la. Por outro lado, a responsabilidade será solidária se houver mais de um responsável pela obrigação, podendo o lesado exigi-la de qualquer um, integral ou parcialmente, cabendo ação regressiva contra o responsável solidário que não contribuiu para reparação do dano (CASTRO, 2014).

\section{Responsabilidade Civil Estatal}

A princípio, dentro da concepção do absolutismo e da infalibilidade do monarca, inadmitia-se a responsabilização do Estado. Todavia, posteriormente, surge a necessidade, e a possibilidade, de responsabilização estatal, sendo três as principais correntes doutrinárias: a da culpa, a do acidente administrativo e a do risco administrativo (PEREIRA, 2018).

A teoria da culpa exige a presença de dolo ou de culpa na conduta do agente estatal, sendo que este deve ter procedido no exercício e no limite de suas atribuições. Caso o dano ocorra no extrapolamento de suas funções ou fora do exercício destas, o Estado estará exonerado de responsabilização civil. Contudo, é prescindível distinguir a culpa pessoal do servidor da culpa do próprio serviço, haja vista que o Estado age pelos seus órgãos e por meio de seus agentes, tendo responsabilidade direta em ambas as hipóteses (PEREIRA, 2018).

Para a teoria do acidente administrativo, por sua vez, basta a comprovação da existência de uma falha objetiva do serviço público, o mau funcionamento deste, ou uma irregularidade anônima que importa em desvio da normalidade. Não é preciso a caracterização da culpa no procedimento do agente, mas tão somente um funcionamento passivo do serviço público que gerou dano. Nesse ínterim, a falta, não cumprimento, ou realização de forma deficiente ou tardia é suficiente para dar ensejo à responsabilização do Estado (PEREIRA, 2018).

Por fim, a teoria do risco administrativo preceitua a prescindibilidade da culpa do agente ou do serviço público, sendo suficiente a existência de um dano sofrido em decorrência do funcionamento do serviço público. Assim, se restar configurada uma relação de causalidade entre o dano e a conduta do 
agente ou órgão públicos, ficará esculpida a responsabilidade civil do Estado. De tal modo, surge uma espécie de "seguro social suportado pela caixa coletiva, em proveito de quem sofre um prejuízo causado pelo funcionamento do serviço público". (PEREIRA, 2018, p. 173).

Da análise do ordenamento jurídico brasileiro, constata-se que este aderiu à teoria do risco administrativo, no tocante ao poder administrativo, conforme salienta Pereira (2018, p. 174):

\begin{abstract}
A pessoa jurídica de direito público responde sempre, uma vez que se estabeleça o nexo de causalidade entre o ato da Administração e o prejuízo sofrido. Não há que cogitar se houve ou não culpa, para concluir pelo dever de reparação. A culpa ou dolo do agente somente é de se determinar para estabelecer a ação de in rem verso, da Administração contra o agente. Quer dizer: o Estado responde sempre perante a vítima, independentemente da culpa do servidor. Este, entretanto, responde perante o Estado, em se provando que procedeu culposa ou dolosamente.
\end{abstract}

Quanto ao Poder Legislativo, verifica-se que o Brasil optou pela teoria objetiva, devendo ser apurada tão somente a ocorrência do dano. Relativamente ao Poder Judiciário, por sua vez, vem-se permitindo a responsabilização do Estado em um crescente por erros judiciais decorrentes de dolo e de culpa, apesar das acentuadas divergências na doutrina e na jurisprudência (PEREIRA, 2018).

\section{Responsabilidade Civil do Estado Perante os Atos de Registradores e Notários}

Considerando o caráter público do serviço notarial e registral, faz-se pertinente a análise da responsabilidade do Estado, conforme salienta Velter Junior (2018, p. 128):

\begin{abstract}
A atividade, ainda que se remeta à satisfação de interesses de direito privado, configura-se em administração pública desses interesses. Com efeito, a competência para outorgar fé pública e o caráter de imperium investido revela se tratar a atividade de função pública, visto não poder efetivar-se sem a participação do Estado. Os atos praticados, portanto, revestem-se de todos os atributos dos atos administrativos e sujeitam-se aos requisitos do direito administrativo.
\end{abstract}

Apesar das peculiaridades do sistema de delegação, verifica-se que os notários e registradores são particulares que atuam em colaboração com o Estado, exercendo função pública, em nome próprio, sob a supervisão do poder público, caracterizando-se, assim, como agentes públicos. Dessarte, sendo o serviço público, mesmo que executado por particulares por meio de delegação, é evidente que o Estado é responsável por danos causados em razão deste, haja vista que estes danos "decorrem de um poder cuja utilização só foi possível por investidura estatal" (VELTER JUNIOR, 2018, p. 129). Nesse toar, faz-se imperiosa a definição da extensão da responsabilidade estatal.

\section{Histórico da Responsabilidade Civil do Estado Perante os Atos de Registradores e Notários}

A jurisprudência brasileira, mesmo antes da Constituição de 1988, sempre foi firme ao reconhecer a responsabilidade estatal por atos praticados por notários e registradores. A divergência sempre residiu na espécie de responsabilização que caberia ao Estado, se direta ou indireta, subsidiária ou solidária. $\mathrm{O}$ Superior Tribunal de Justiça, inicialmente, fixou o entendimento de que a responsabilidade do Estado era objetiva e direta, podendo este ser demandado de forma exclusiva em 
ações indenizatórias. Tal entendimento, que prevaleceu até 2001, adotava o princípio da culpa para a responsabilização dos titulares de cartório, utilizando, por analogia, o regime dos servidores públicos (VELTER JUNIOR, 2018).

Posteriormente, diante das críticas doutrinárias acerca da equiparação dos notários e registradores aos servidores públicos, para fim de responsabilização civil, passou-se a adotar o entendimento de que a responsabilidade estatal seria objetiva e subsidiária, devendo o Estado ser responsabilizado tão somente no caso de insolvência do agente delegado. Tal corrente "sustenta que é da essência da delegação a assunção de riscos" (VELTER JUNIOR, 2018, p. 137), tendo os notários e registradores autonomia administrativa e financeira na gerência dos cartórios, devendo, assim, ser diretamente responsáveis pelos danos causados em razão de sua atividade. Tal posicionamento consagrou a responsabilidade objetiva e direta dos notários e registradores (VELTER JUNIOR, 2018).

Todavia, com o advento da Lei $\mathrm{n}^{\circ}$ 13.286/16, a responsabilidade dos agentes delegados passou a ser, novamente, subjetiva e direta, assim, para sua responsabilização, passou a ser necessária a ocorrência de dolo ou de culpa (FERREIRA, 2018). Conforme apontam Lamanauskas; Pedroso (2018, s.p.):

Em relação à esfera de atuação pública a responsabilidade do Estado é objetiva, pois se trata de responsabilidade quanto à aplicação das normas e condutas comuns do sistema, da estrutura. Por outro lado, há a esfera privada, quanto à administração particular das serventias e principalmente pela qualificação dos documentos. A qualificação é subjetiva e, portanto, a responsabilidade desta só pode ser atribuída a quem a fez, de modo pessoal. O oficial que atua conferindo segurança jurídica por vezes analisa a legalidade e conformidade do que se pretende registrar e neste momento atua com responsabilidade.

Nesse contexto, ressurgem os questionamentos acerca da responsabilidade estatal, principalmente no campo processual, haja vista que esta repercutirá diretamente na legitimação passiva, no ônus da prova, no mérito da ação e até mesmo em matéria de prescrição (CASTRO, 2014). Ademais, ressalta-se o questionamento acerca da possível inconstitucionalidade da Lei no $13.286 / 16$, questão enfrentada pelo Superior Tribunal Federal no recurso extraordinário com repercussão geral $n^{\circ} 842.846$ interposto pelo estado de Santa Catarina (PESSOA, 2017).

\section{Lei $n^{\circ} 13.268 / 16$ e a Decisão Paradigma RE 842.846 STF}

Tendo em vista tal panorama, em 06 de novembro de 2014 o plenário do Superior Tribunal Federal admitiu a repercussão geral no recurso extraordinário $n^{\circ} 842.846$. Trata-se este de recurso interposto pelo estado de Santa Catarina em face do acórdão prolatado pelo Tribunal de Justiça de Santa Catarina, que desproveu a apelação interposta em face da sentença de primeiro grau e que atribuiu ao Estado a responsabilidade objetiva e direta por atos praticados por tabeliães, sendo este o responsável pelo pagamento da indenização pleiteada pela vítima. $\mathrm{O}$ recurso foi pautado e julgado em 27 de fevereiro de 2019 (STF, 2019).

Apesar das divergências entre os ministros, a maioria acompanhou o voto do relator, ministro Luiz Fux, que assentou a seguinte tese: "o Estado responde, objetivamente, pelos atos dos tabeliães e registradores oficiais que, no exercício de suas funções, causem dano a terceiros, assentado o dever de regresso contra o responsável, nos casos de dolo ou culpa, sob pena de improbidade administrativa" (STF, 2019, s.p.). 
Assim, diante da tese fixada pelo plenário, negou-se provimento ao recurso extraordinário interposto pelo estado de Santa Catarina, devendo este indenizar os danos decorrentes de erro na elaboração de certidão de óbito que impediu o viúvo de obter benefício previdenciário (STF, 2019).

Ressalta-se que o entendimento adotado pelos ministros reafirma o posicionamento da Corte "quanto à responsabilização direta, primária e objetiva do Estado [...] pelos danos que tabeliães e oficiais de registro, no exercício de serviço público por delegação, causem a terceiros" (STF, 2019, s.p.), a qual foi insculpida no parágrafo $6^{\circ}$, artigo 37 , da Constituição de 1988. Haja vista que, conforme estabelece a teoria do risco, os danos que o Estado causar no desempenho de missões de interesse público devem ser socializados, considerando a iniquidade de que apenas alguns arquem com os prejuízos decorrentes de atividades exercidas em proveito da coletividade (CASTRO, 2014).

Ademais, alicerçou-se o dever do Estado de "acionar regressivamente o agente público causador do dano, por dolo ou culpa, considerado o fato de a indenização ser paga com dinheiro público" (STF, 2019, s.p.). Assim, caso o agente atue em desconformidade com o múnus público, deverá ser demandado em ação regressiva pelo Estado, tendo em vista que não cabe à sociedade arcar com a desídia dos agentes públicos em sua atuação (CASTRO, 2014). Tal interpretação vai de encontro à posição firmada pela Lei $n^{\circ} 13.268 / 16$, que regulamentou o parágrafo $1^{\circ}$ do artigo 236 da Constituição de 1988, restando assim afastada a inconstitucionalidade arguida por diversos doutrinadores (VELTER JUNIOR, 2018).

Frisou, no ponto, que o art. 22 da Lei $8.935 / 1994$, na redação dada pela Lei 13.286/2016, regulamenta o art. 236 da $\mathrm{CF} / 1988$ e prevê que os notários e oficiais de registro são civilmente responsáveis por todos os prejuízos que causarem a terceiros, por culpa ou dolo, pessoalmente, pelos substitutos que designarem ou escreventes que autorizarem, assegurado o direito de regresso. A disciplina conferida à matéria pelo legislador consagra a responsabilidade civil subjetiva dos notários e oficiais de registro. Portanto, não compete ao STF fazer interpretação analógica e extensiva, a fim de equiparar o regime jurídico da responsabilidade civil de notários ao das pessoas jurídicas de direito privado prestadoras de serviços públicos $(\mathrm{CF}$, art. 37 , $\S 6^{\circ}$ ). Ademais, ressaltou que o art. $37, \S$ $6^{\circ}$, da CF/1988 se refere a "pessoas jurídicas" prestadoras de serviços públicos, ao passo que notários e tabeliães respondem civilmente como "pessoas naturais" delegatárias de serviço público, nos termos do referido dispositivo legal (STF, 2019, s.p.).

\section{Conclusão}

Diante da análise da decisão do Supremo Tribunal Federal no recurso extraordinário $\mathrm{n}^{\circ}$ 842.846, verifica-se que restou definida a responsabilidade civil do Estado perante os atos praticados por notários e registradores, bem como a responsabilidade civil dos próprios registradores e notários. Assim, consagrou-se a responsabilização estatal objetiva e direta, devendo o Estado ser diretamente demandado pelo lesado em ação indenizatória; também restou afastado o questionamento da doutrina acerca da inconstitucionalidade da Lei $n^{\circ}$ 13.268/16, confirmando-se a responsabilidade subjetiva do agente público.

Contudo, verifica-se que diversos questionamentos ainda não foram solucionados, haja vista que ainda resta em aberto a maioria das indagações processuais anteriormente presentes. Percebe-se que não restou delineada a legitimação passiva, bem como a hipótese de denunciação da lide, mas tão somente o dever do Estado propor ação regressiva em 
face do notário e do registrador que agiu com dolo ou culpa no exercício de suas funções. Caso o litisconsórcio seja permitido, surge a questão do ônus da sucumbência e do ônus da prova, situações que também permanecem controversas.

Além disso, destaca-se que a possibilidade de responsabilização direta do Estado leva a uma socialização extrema dos danos, onerando-o de forma excessiva, haja vista que, antes mesmo da apuração de possível culpa ou dolo do agente público, bem como de sua responsabilização em primeiro plano, caberá ao Estado o pagamento de indenização. Sobejando ao Estado tão somente a propositura de ação regressiva contra o notário ou registrador displicente. Assim, o
Estado é novamente onerado com o custo da propositura de nova demanda judicial, a qual poderá ser inexitosa, tendo em vista a possibilidade do agente público encontrar-se em estado de insolvência.

Nessa conjuntura, constata-se que apesar de restar dimensionada a responsabilização estatal, pelos atos dos notários e registradores, ainda é preciso uma grande evolução jurisprudencial e legislativa, especialmente em matéria processual, a fim de que seja assegurada a ordem constitucional e a segurança jurídica. Dessarte, resta aos operadores do direito a análise deste instituto e a propositura de possíveis soluções para os questionamentos decorrentes da paradigmática decisão proferida pela suprema corte brasileira.

\section{REFERÊNCIAS}

BRASIL. Superior Tribunal Federal. Informativo no 87. Disponível em: http://www.stf.jus.br/ arquivo/cms/publicacaoInformativoTema/anexo/2019maro2019.html. Acesso em: 10 jul. 2019.

BRASIL. Superior Tribunal Federal. Acórdão RE 842846/RJ. Disponível em: http://redir.stf.jus.br/ paginadorpub/paginador.jsp?docTP=TP\&docID=7251059. Acesso em: 10 jul. 2019.

CASTRO, D. M. Responsabilidade civil na atividade notarial e registral. 2014. 224 f. Dissertação (Mestrado em Direito), USP, São Paulo, SP, 2014. Disponível em: http://www.teses.usp.br/teses/ disponiveis/2/2131/tde-06112015-160939/en.php. Acesso em: 10 jul. 2019.

FERREIRA, P, R. G.; RODRIGUES, F. L. Tabelionato de notas I: teoria geral do direito notarial e minutas. 2. ed. São Paulo: Saraiva, 2018.

GONÇALVES, C. R. Direito civil brasileiro: responsabilidade civil. 13. ed. São Paulo: Saraiva, 2018.

MARTINS, M. T. A responsabilidade civil dos notários e oficiais de registro. 2017. $54 \mathrm{f}$.

Monografia (Graduação em Direito), UNISUL, Araranguá, SC, 2017. Disponível em: https://riuni. unisul.br/handle/12345/3811. Acesso em: 10 jul. 2019.

PEDROSO, R.; LAMANAUSKAS, M. F. Direito notarial e registral atual. 2. ed. São Paulo: Forense, 2015.

PESSOA, H. M. Responsabilidade civil: inconstitucionalidade da lei 13.286/2016. 2017. 58 f. Monografia (Graduação em Direito), FIC, Caratinga, MG, 2017. Disponível em: http://dspace. doctum.edu.br:8080/handle/123456789/317. Acesso em: 10 jul. 2019.

PEREIRA, C. M. S. Responsabilidade civil. 12. ed. Rio de Janeiro: Forense, 2018.

VELTER JUNIOR, M. M.. Responsabilidade civil por atos praticados por notários e registradores. 2018. 215 f. Dissertação (Mestrado em Direito) - UFSC, Florianópolis, SC, 2018 Disponível em: http://150.162.242.35/handle/123456789/189501. Acesso em: 10 jul. 2019. 